\title{
Sudden occurence of hypotension and bradycardia during greenlight laser transurethral resection of prostate: case report of two cases
}

\author{
Zheng Guan ${ }^{1}$ and Jingjie Liư ${ }^{2 *}$
}

\begin{abstract}
Background: Greenlight laser transurethral resection of prostate (TURP) is a standard surgical method used to treat patients with prostate gland enlargement, it is safe and effective.

Case presentation: We report two cases of sudden occurence of hypotension and bradycardia during greenlight laser TURP. Two patients with benign prostatic hypertrophy were scheduled for greenlight laser TURP under spinal anesthesia. Hypotension and bradycardia were suddenly occurred during the operation. The blood gas analysis revealed no hyponatremia (indicating TURP syndrome) or anemia (indicating hemorrhage). Operation was suspended and inotropic agents were administrated intravenous immediately, then blood pressure and heart rate increased to normal level within some minutes. The patients were discharged from hospital without any complications. We considered parasympathetic reflex was occurred during greenlight laser TURP.

Conclusion: Apart from TURP syndrome, hemorrhage, bladder perforation and high spinal anesthesia, the parasympathetic reflex which is caused by operative process can also induce hypotension and bradycardia during TURP.

Keywords: Parasympathetic reflex, Transurethral resection of prostate, Greenlight laser

Abbreviations: BP, Blood pressure; bpm, Beat per minute; ECG, Electrocardiogram; EF, Ejection fraction; Hct, Haematocrit; HR, Heart rate; NYHA, New York Heart Association; PACU, Post anesthesia care unit; PCI, Percutaneous coronary intervention; TURP, Transurethral resection of prostate; UCG, Ultrasound echocardiography
\end{abstract}

\section{Background}

Greenlight laser transurethral resection of the prostate (TURP) is a standard surgical method used to treat patients with prostate gland enlargement. Hypotension and bradycardia are complications of TURP, the primary causes are TURP syndrome, hemorrhage and bladder perforation [1,2], high spinal anesthesia is also a common cause [3]. But we report other two cases who presented sudden and severe hypotension and bradycardia during greenlight laser TURP which wasn't due to reasons above, but due to parasympathetic reflex. To the best of our knowledge, this is the first report that parasympathetic reflex can cause hypotension and bradycardia during greenlight laser TURP. We suggest that the strict monitoring of vital signs should be performed and the vasoactive drugs should be prepared during TURP, the heart rate and blood pressure should be maintained at a higher level during TURP, and the decline of heart rate and blood pressure should be intervened immediately. This study has been granted an exemption from requiring ethics approval according to "The ethics committee of the first affiliated hospital of Xi'an jiaotong unversity".

\footnotetext{
* Correspondence: liujjxing8008@126.com

2Department of Neurology, The Second Affiliated Hospital of Xi'an Jiaotong

University, Xi'an, China

Full list of author information is available at the end of the article
} 


\section{Case presentation \\ Case one}

A 78-year-old man underwent TURP due to benign prostatic hyperplasia, there were no coexisting diseases. The operation was performed under spinal anesthesia with $2 \mathrm{ml} 0.5 \%$ hyperbaric bupivacaine and at lithotomy position. The sensory block level was extended to the T10. The heart rate (HR) was $72 \mathrm{bpm}$ and blood pressure (BP) was $140 / 75 \mathrm{mmHg}$ at the start of the operation, the SpO2 was $100 \%$ and the electrocardiograph (ECG) was normal. The TURP was performed by greenlight laser instrument. The irrigation fluid was $0.9 \%$ normal saline. A hour later, when the operation site focused on the apex of prostate, the HR suddenly decreased to $38 \mathrm{bpm}$, the BP dropped to $68 / 36 \mathrm{mmHg}$, patient appeared nausea and pallor. The operation was suspended immediately, the $1 \mathrm{mg}$ atropine was administrated intravenous, but the HR was not rised, then the dopamine was continuous infusioned at a dose of 5-10 ug. $\mathrm{kg}^{-1} \cdot \mathrm{min}^{-1}$ after a bolus of $1 \mathrm{mg}$ intravenous. The BP and HR slowly increased and returned to normal $30 \mathrm{~min}$ later. The blood gas analysis revealed the serum sodium was $138.1 \mathrm{mmol} / \mathrm{l}$, the Hct was $27 \%$ (28.4 \% preoperation), the acid-base balance was normal. The operation was ended after tight hemostasis, the patient was recovered uneventful and discharged from hospital 7 days later in a good condition.

\section{Case two}

A 65-year-old man underwent TURP due to benign prostatic hyperplasia, he was administrated a PCI due to acute cardiac infarction 5 years ago. The ultrasonic cardiography (UCG) indicated the eject fraction (EF) was $45 \%$, the cardiac function was III degree according to the New York Heart Association (NYHA). The operation and anesthesia were performed as same as the case one. The HR was $75 \mathrm{bpm}$ and BP was $116 / 72 \mathrm{mmHg}$ at the start of the operation, the $\mathrm{SpO} 2$ was $100 \%$ and the ECG was normal. 40 min later, when the operation site focused on the apex of prostate, the HR suddenly decreased to $32 \mathrm{bpm}$, the BP dropped to $60 / 35 \mathrm{mmHg}$, patient became restless and agonal. The operation was suspended and the $0.5 \mathrm{mg}$ atropine was administrated intravenous immediately, he was intubated and ventilated with an $\mathrm{FiO} 2$ of $60 \%$ after general anesthesia induction $(0.1 \mathrm{mg}$ fentanyl, $15 \mathrm{mg}$ etomidate, $50 \mathrm{mg}$ rocuronium, sequential), invasive blood pressure monitor was performed through brachial artery caheter. Epinephrine was continuous infusioned at a dose of $0.03-0.1$ ug. $\mathrm{kg}^{-1} \cdot \mathrm{min}^{-1}$. The BP and HR increased to $102 \mathrm{bpm}$ and $140 / 79 \mathrm{mmHg}$ respectively five minutes later. The blood gas analysis revealed the serum sodium was $140 \mathrm{mmol} / \mathrm{l}$, the Hct was $33 \%$ (36\% preoperative), the acid-base balance was normal. The ECG was identified that acute myocardiac ischemia and acute coronary syndrome were not occured. The operation was ended after tight hemostasis, the patient was recovered in postanesthesia care unit (PACU) and extubated $30 \mathrm{~min}$ after operation, he made an uneventful recovery and was discharged from hospital 9 days later in a good condition. The arterial blood gas analysis and electrolyte levels of the two patients were displayed in Table 1.

\section{Discussion}

Hypotension and bradycardia were common complications during TURP, the reason of these complications are TURP syndrome, hemorrhage, bladder perforation and high spinal anesthesia. The TURP syndrome is a systemic complication caused by excessive absorption of electrolyte-free irrigation fluids [4], the incidence is $0.78-1.4 \%$ [2]. The incidence of bladder perforation is $1 \%$ during TURP [5]. We reported other two cases who presented sudden severe hypotension and bradycardia during greenlight laser TURP which weren't due to TURP syndrome, hemorrhage or bladder perforation and high spinal anesthesia, but due to parasympathetic reflex.

We suspected it was parasympathetic reflex that lead to hypotension and bradycardia in these two patients. First, the hypotension and bradycardia occured suddenly, the symptom was similar to the classic vagal reflex caused by pulling reaction of viscera during appendectomy under epidural anesthesia [6]. Second, the symptom was improved when the operation was suspended and the atropine and inotropic drugs were used, they were also as same as the treatment of vagal reflex. Third, the symptom was occured when the same operative process was performed. It could be explained by a neural reflex.

Table 1 The arterial blood gas analysis and electrolyte levels of the two patients

\begin{tabular}{|c|c|c|c|c|}
\hline \multirow[t]{2}{*}{ Patient } & \multicolumn{2}{|c|}{ Case one } & \multicolumn{2}{|c|}{ Case two } \\
\hline & $\mathrm{T} 1$ & $\mathrm{~T} 2$ & $\mathrm{~T} 1$ & $\mathrm{~T} 2$ \\
\hline $\mathrm{pH}$ & 7.377 & 7.377 & 7.405 & 7.418 \\
\hline $\mathrm{PCO} 2(\mathrm{mmHg})$ & 40.5 & 42.6 & 40.8 & 39.6 \\
\hline $\mathrm{PO} 2(\mathrm{mmHg})$ & 154.1 & 119.8 & 114 & $346^{2}$ \\
\hline $\operatorname{Hct}(\%)$ & $27^{\circledR}$ & 28.4 & 33 & 30 \\
\hline $\mathrm{K}+(\mathrm{mmol} / \mathrm{l})$ & 3.23 & 3.18 & 4.3 & 4.2 \\
\hline $\mathrm{Na}+(\mathrm{mmol} / \mathrm{l})$ & 138.1 & 139.2 & 140 & 138 \\
\hline $\mathrm{HCO} 3(\mathrm{mmol} / \mathrm{l})$ & 24 & 25.2 & 25.2 & 25.4 \\
\hline $\mathrm{BE}(\mathrm{mmol} / \mathrm{l})$ & -1.4 & -0.2 & 0.9 & 1.1 \\
\hline Glucose(mmol/l) & 10.9 & 7.71 & 8.2 & 5.2 \\
\hline Lactate(mmol/l) & 2.8 & 0.8 & 1.6 & 0.8 \\
\hline
\end{tabular}

$T 1$ The time point when hypotension and bradycardia occured, $T 2$ the time point when the patients' condition became stable, (1): preoperative $\mathrm{Hct}$ is $28.4 \%$; (2): mechanical ventilated with $\mathrm{FiO} 2$ of $60 \%$ 
The prostate anatomic position also related to parasympathetic activity, because prostate is surrounded by autonomic nerve fibers including sympathetic and parasympathetic nerves. The parasympathetic nervous center is located at S2-S4 section of spinal cord. The peripheral part is composed of inferior hypogastric plexus and pelvic splanchnic nerve. In which, pelvic splanchnic nerve is closer to the apex of prostate at the level of the membranous urethra. Besides, the parasympathetic nerves were mainly located dorsolaterally at the apex according to immunohistochemical analysis $[7,8]$.

Hypotension and bradycardia are common adverse effects of spinal anesthesia, the incidence is $15-38 \%$ and $10 \%$ respectively [3]. They usually occur in elder patients [9] and they usually occur at the beginning $15 \mathrm{~min}$ of intrathecal injection [10]. High spinal block (above T5) $[11,12]$ and high dose of heavy bupivacaine [12] are main anesthetic factors. But in the two cases we reported here, the hypotension and bradycardia occurred 40$60 \mathrm{~min}$ after intrathecal injection. And the spinal puncture was performed at the L3-4 intervertebral space, the level of sensory block was below T10 throughout the operation. The dose of bupivacaine was well controlled. So we think hypotension and bradycardia in our cases were caused by parasympathetic reflex instead of high spinal anesthesia.

The hypotension and bradycardia in our cases were not caused by TURP syndrome. First, TURP syndrome can cause hypervolemia and hyponatraemia [4], but it is rare when normal saline is used as irrigation fluid [13]. In our cases, normal saline is used as irrigation fluid, and there is no manifestation of hypervolemia and hyponatraemia. Second, TURP syndrome can cause a wide variety of symptoms including asymptomatic hyponatremia, ECG changes, fatigue, vomiting, confusion, visual loss, coma and death [14, 15]. So the change of mental state may be the first sign, but it was not appeared in our cases. Third, we didn't give any treatment of TURP syndrome such as sedation, diuresis and sodium supplement [16], the cases recovered. Finally, TURP syndrome is defined as serum sodium concentration $\leq 125 \mathrm{mmol} / \mathrm{l}$ [17], but it was normal in our cases.

The intravesical explosion during TURP can cause bradycardia and hypotension, accompany with nausea, abdominal pain and developed confusion [1]. But this complication usually manifested as a "pop" and can be identified by the urologists and anesthesiologists. The bladder perforation can be observed through cystoscope. So the hypotension and bradycardia in our cases were not caused by bladder perforation.

Because the Hct was stable during operation, the hypotension and bradycardia were not caused by hemorrhage.

\section{Conclusion}

Apart from TURP syndrome, hemorrhage, bladder perforation and high spinal anesthesia, parasympathetic reflex during TURP is another reason which can cause hypotension and bradycardia. We suggest that the strict monitoring of vital signs should be performed and the vasoactive drugs should be prepared during TURP. Don't forget the possibility of parasympathetic reflex when sudden hypotension and bradycardia appeared in TURP.

\section{Acknowledgements}

The authors thank doctor Lin Yang, Department of Urology Surgery, the First Affiliated Hospital of Xi'an Jiaotong University, Xi'an, China for his insightful analysis of the cause of hypotension and bradycardia.

\section{Funding}

None.

\section{Availability of data and materials}

The case numbers of our study were No.1140272 and No.1279632 respectively in the first affiliated hospital of Xi'an jiaotong unversity. All the data supporting our findings were presented in this article.

\section{Authors' contributions}

GZ: Involvement in the cases, preparation of the manuscript, acquisition and analysis the data of the article. LJ: Read and approved the final manuscript to be published. Both authors read and approved of the final version of the manuscript.

\section{Competing interests}

The authors declare that they have no competing interests in the cases.

\section{Consent for publication}

A written informed consent was obtained from the patients for publication of this case report.

\section{Ethics approval and consent to participate}

This study has been granted an exemption from requiring ethics approval according to "The ethics committee of the first affiliated hospital of Xi'an jiaotong unversity".

\section{Author details}

'Department of Anesthesiology, The First Affiliated Hospital of Xi'an Jiaotong University, Yanta West Road, No.277, 710061 Xi'an, China. ${ }^{2}$ Department of Neurology, The Second Affiliated Hospital of Xi'an Jiaotong University, Xi'an, China.

Received: 8 January 2016 Accepted: 24 August 2016

Published online: 30 August 2016

\section{References}

1. Oğuz G, Subaşı D, Kaya M, Güven O, Ünver S. Intravesical explosion: a rare complication of transurethral resection of prostate. J Anesth. 2013;27(1):145-6.

2. Zepnick H, Steinbach F, Schuster F. Value of transurethral resection of the prostate (TURP) for treatment of symptomatic benign prostaticobstruction (BPO): an analysis of efficiency and complications in 1015 cases. Aktuelle Urol. 2008;39(5):369-72.

3. Hartmann B, Junger A, Klasen J, Benson M, Jost A, Banzhaf A, et al. The incidence and risk factors for hypotension after spinal anesthesia induction: an analysis with automated data collection. Anesth Analg. 2002;94(6):1521-9.

4. Hahn RG. Transurethral resection syndrome after transurethral resection of bladder tumours. Can J Anaesth. 1995;42(1):69-72.

5. Hahn RG. The volumetric fluid balance as a measure of fluid absorption during transurethral resection of the prostate. Eur J Anaesthesiol. 2000;17(9):559-65. 
6. Ke YC, Yi HD, Yang CP, Lee HK, Kuo CP, Wong CS. Clipping of the appendix induced cardiac arrest during appendectomy under spinal anesthesia. Acta Anaesthesiol Taiwan. 2005;43(3):183-6.

7. Ganzer R, Stolzenburg JU, Wieland WF, Bründl J. Anatomic study of periprostatic nerve distribution: immunohistochemical differentiation of parasympatheticand sympathetic nerve fibres. Eur Urol. 2012;62(6):1150-6.

8. Costello AJ, Dowdle BW, Namdarian B, Pedersen J, Murphy DG. Immunohistochemical study of the cavernous nerves in the periprostatic region. BJU Int. 2011;107(8):1210-5.

9. Meyhoff CS, Haarmark C, Kanters JK, Rasmussen LS. Is it possible to predict hypotension during onset of spinal anesthesia in elderly patients? J Clin Anesth. 2009;21(1):23-9.

10. Ketelaars R, Wolff AP. Unexpected high sensory blockade during continuous spinal anesthesiology (CSA) in an elderly patient. Case Rep Anesthesiol. 2012:2012:648921.

11. Sirivararom P, Virankabutra T, Hungsawanich N, Premsamran P, Sriral W. The thai anesthesia incidents monitoring study(thai AIMS) of adverse events after spinal anesthesia: an analysis of 1996 incident reports. J Med Assoc Thai. 2009;92(8):1033-9.

12. Chinachoti T, Tritrakarn T. Prospective study of hypotension and bradycardia during spinal anesthesia with bupivacaine: incidence and risk factors, part two. J Med Assoc Thai. 2007:90(3):492-501.

13. Richter T, Huebler M. Acute abdominal compartment syndrome as a complication of Holmium laser enucleation of the prostate: a case report. BMC Anesthesiol. 2014;14:32.

14. Rassweiler J, Teber D, Kuntz R, Hofmann R. Complications of transurethral resection of the prostate (TURP)-incidence, management, and prevention. Eur Urol. 2006;50(5):969-79.

15. Nakahira J, Sawai T, Fujiwara A, Minami T. Transurethral resection syndrome in elderly patients: a retrospective observational study. BMC Anesthesiol. 2014;14:30.

16. Demirel I, Ozer AB, Bayar MK, Erhan OL. TURP syndrome and severe hyponatremia under general anaesthesia. BMJ Case Rep. 2012;19:page number not for citation purposes.

17. Michielsen DPJ, Debacker T, De Boe V, Van Lersberghe C, Kaufman L, Braeckman JG, et al. Bipolar transurethral resection in saline-an alternative surgical treatment for bladder outlet obstruction. J Urol. 2007;178(5):2035-9.

\section{Submit your next manuscript to BioMed Central and we will help you at every step:}

- We accept pre-submission inquiries

- Our selector tool helps you to find the most relevant journal

- We provide round the clock customer support

- Convenient online submission

- Thorough peer review

- Inclusion in PubMed and all major indexing services

- Maximum visibility for your research

Submit your manuscript at www.biomedcentral.com/submit

) Biomed Central 